\title{
The effects of nursing welcome program on the level of stress and satisfaction of patients in the Coronary Care Unit Shahla Biglar ${ }^{1}$, Abolhassan Rafiee ${ }^{2}$, Maryam Puryaghoob ${ }^{1}$, Fariba Sharafi ${ }^{1}$, Fatemeh Moghaddam $^{3 *}$, Zahra Nisari ${ }^{4}$
}

1. Nursing Department, Abhar School of Nursing, Zanjan University of Medical Sciences, Zan-jan, Iran.

2. Al-Ghadir Abhar Hospital, Zanjan University of Medical Sciences, Zanjan, Iran.

3. Nursing Department, Abhar School of Nursing, Zanjan University of Medical Sciences, Zan-jan, Iran.

4. Statistician, Abhar Health Network, Zanjan University of Medical Sciences, Zanjan, Iran.

*Correspondence: Nursing Department, Abhar School of Nursing, Zanjan University of Medical Sciences, Zanjan, Iran. Tel: +98-9191464335. Email: fateme.mogadam124@ gmail.com

Received Sep 01, 2018; Accepted July 20, 2019

\section{Abstract}

Background: The management of Psychological symptom in patients and nurses, effective communication with patients are important issues that should be taken into consideration in nursing care. This study aimed to examine the effects of nursing welcome program on the level of stress and satisfaction in patients in the Coronary Care Units (CCU). Methods: The interventional study was done on 72 patients, who were admitted to CCU at Emdadi hospital in Abhar in 2017. The patients were selected by convenience sampling and were allocated into intervention $(n=36)$ and control $(n=36)$ groups. Data was collected using a questionnaire including demographic; Depression, Anxiety and Stress Scale (DASS-21), and the La Monica-Oberst Patient Satisfaction Scale (LOPSS). The DASS-21 was fulfilled by a welcome nurse through interview in both groups. Then the welcome nurse began to implement the Nursing Welcome Program in the intervention group. The level of patients' stress and satisfaction were measured an hour and 24 hours after the intervention respectively. Patients in the control group received routine care without any intervention. Data was analyzed using independent t-test, chi-square test, and Fisher's exact test in SPSS-16. Results: The Mean \pm SD of stress in intervention and control groups after intervention were $8.23 \pm 3.24$ and $11.9 \pm 4.20$ respectively $(\mathrm{p}=0.001)$. The Mean \pm SD of satisfaction in intervention and control groups after intervention were 249.26 \pm 26.7 and $236.10 \pm 23.71$ respectively $(\mathrm{p}=0.031)$.

Conclusions: According to the importance of nurses' position in communicating with patients, 
employing welcome nurses as an effective care method to reduce psychological symptoms and increase patients' satisfaction is suggested.

Keywords: Stress, Satisfaction, Nurses, Coronary Care Units

$\underline{10.29252 / \text { jgbfnm.16.2.11 }}$

\section{Introduction}

Cardiovascular diseases are increasing in developing countries (1). Coronary artery disease is the most common chronic and life-threatening disease (2). Acute coronary syndrome is a manifestation of coronary artery disease with psychological manifestations such as stress and anxiety besides physical manifestations such as pain, sweating and vomiting (3). The results of a screening study indicated that cardiac patients showed $72 \%$ of depression symptoms and $90 \%$ of prevalence of anxiety symptoms (4). Stress and anxiety increase heart rate and left ventricular pressure which in turn lead to increase the need of myocardium for more oxygen, thereby increasing the process of ischemia and myocardial necrosis and delaying the recovery process will occur (5). These patients experience stress and anxiety due to hospitalization, fear of death and heart surgery, and generally due to a lack of awareness and fear of the unknowns as well as being present in an unfamiliar hospital environment. The excessive anxiety and stress may delay the recovery process $(3,6,7)$. The medications used in the treatment of stress and anxiety in heart patients, despite decreasing the symptoms, are associated with many side effects.

Studies indicate that good communication with patients is effective in reducing anxiety and increasing satisfaction. Nurses can play important roles in controlling consequences of diseases in addition to informing and pre-admission patient educating by establishing effective therapeutic relationships and empathy with patients as well as creating a safe and comfortable environment (8-10). Despite the fact that some previous studies indicate nursing weakness in establishing good communication with patients (11), the results of other researches on quality of nursing care and nurses' satisfaction exhibited that in the face of considerable efforts in this field, we have not yet achieved the goal $(12,13)$. Fulfilling the patient satisfaction is essential since their satisfaction plays an important role in improving their physical and mental status which ultimately improves the social health (14). This study aimed to examine the effects of nursing welcome program on the level of stress and satisfaction in patients in the Coronary Care Units.

\section{Methods}

The present study was a pre-test post-test interventional research with a control group which was conducted in the CCU of Emdadi Hospital of Abhar in 2017. The research population consisted of patients hospitalized in the CCU. The sample size was estimated to be 72 according to a previous study (15), and the test power of $80 \%$, and $95 \%$ confidence level was obtained based on the following equation:

$$
n=\frac{\left(z_{1-\alpha / 2}+z_{1-\beta}\right)^{2}\left(s_{1}^{2}+s_{2}^{2}\right)}{d^{2}}
$$

The patients were recruited through convenience sampling (within 7 months) based on the inclusion criteria, and were allocated into intervention $(n=36)$ and control $(n=36)$ groups using quadric-blocks. 
The quadric-blocks were used to place study participants $(n=72)$ in individual intervention and control groups. First, all quadric states (A: control group, B: intervention group) were determined as follows, and then a sample of 72 individuals was selected 18 times from this 6-individual population to reach the target sample size. Afterwards, half of the patients were put in the intervention group and another half in the control group.

The inclusion criteria included the patients with acute coronary syndrome in the age range from 40- to 75years; literate patients; no history of anxiety, depression and stress based on patient's statements; and the history of using anxiolytic, anti-stress and anti-depression drugs according to asking questions from patients. The exclusion criteria included patients' being in acute and critical conditions and unwilling to continue the study. After explaining the research purpose, informed consent was obtained from all the patients and they were told that they had the right to withdraw from the study whenever they wanted, however, none of patients were excluded from the study.

To perform the intervention, the Depression, Anxiety and Stress Scale- 21 Items (DASS-21) were provided for the patients in both groups by the researcher (the welcome nurse) at the beginning of patients' admission to the CCUs. The welcome nurse welcomed patients in the intervention group based on a certain program, called them by names, introduced herself, guided patients to their beds, showed the equipment to them, and provided the following information:

1. Introduction of ward

2. Explanation of ward regulations

3. Explanation of patients' clinical conditions

The welcome nurse played roles at the early hours of patient entry to the ward until the resolution of questions and familiarity of intervention group patients with the ward. In the control group, no measure was taken by the welcome nurse; and patients were admitted according to ward routines. An hour after intervention by welcome nurse, the DASS-21 was again fulfilled by patients in both groups. The patients' satisfaction questionnaire was completed by both groups 24 hours after the intervention. It should be noted that satisfaction rates were measured only once after the intervention.

Data was collected using demographic questionnaire, the Depression, Anxiety and Stress Scale21 Items (DASS-21), and the La Monica-Obverts Patient Satisfaction Scale (LOPSS). DASS was designed in both versions 42 and 21 by Levi band in 1995. In the 21-item version, 7 questions were considered for each emotional state. In this questionnaire, questions 18, 14, 12, $11,8,6$, and 1 were related to stress(16). DASS-21was validated by Ali Sahebi on 870 University students and 200 military personnel in Iran. In this study, the reliability of this scale was 0.78 using Cranach's alpha; and its validity was confirmed through factor analysis and criterion validity (17). The standard La Monica-Oberst Patient Satisfaction Scale (LOPSS) with 41 items was also used to assess the patients' satisfaction based on a 7-point Likert scale ranging from strongly agrees to strongly disagree (18). In a study by Nikmanesh et al., Content Validity Ratio (CVR) and content validity index (CVI) were 0.75 and 0.87 respectively; and reliability of questionnaire was confirmed by Cornbrash's alpha coefficient of 0.89 (19). The reliability of this tool was estimated to be 0.92 using Cornbrash's alpha.

Data was analyzed in SPSS for Windows version 16.00 (SPSS Inc., Illinois, and USA). The independent t-test (comparison of stress levels between intervention and control groups before and after the intervention), paired t-test (comparison of stress levels between two groups before and after the intervention), chi-square test (investigation of gender, occupation, education and 
marital status in both groups) and Fisher's test (investigation of history of hospital admission for both groups) were used. The significance level was considered less than 0.05 .

\section{Results}

In the present study, 72 patients, who were admitted to CCUs, were examined in two intervention $(n=36)$ and control group $(n=36)$ groups. The mean age of patients in the control group was $48 \pm 18$ and in the intervention group was $54 \pm 13$.6. There was no significant difference between two groups in terms of age, gender, marital status, education, occupation, and history of hospitalization. (Table 1)

Table 1. Demographic characteristics of patients in control and Intervention groups

\begin{tabular}{|c|c|c|c|c|c|c|}
\hline \multirow[t]{2}{*}{ Variable } & \multirow[t]{2}{*}{ Group } & \multicolumn{2}{|c|}{ Control } & \multicolumn{2}{|c|}{ Intervention } & \multirow[t]{2}{*}{ P-value } \\
\hline & & $\mathrm{N}$ & $\%$ & $\mathrm{~N}$ & $\%$ & \\
\hline \multirow[t]{2}{*}{ gender } & Male & 22 & 45.8 & 26 & 54.2 & \multirow[t]{2}{*}{$0.399 *$} \\
\hline & Female & 13 & 56.5 & 10 & 43.6 & \\
\hline \multirow[t]{3}{*}{ Marital status } & Married & 31 & 86.1 & 29 & 83.9 & \multirow[t]{3}{*}{$0.126^{*}$} \\
\hline & Single & 2 & 5.6 & 4 & 11.4 & \\
\hline & Widowed and divorced & 3 & 8.3 & 2 & 5.7 & \\
\hline \multirow[t]{4}{*}{ Education status } & Illiterate & 6 & 16.7 & 3 & 8.6 & \multirow[t]{4}{*}{$0.496^{*}$} \\
\hline & Under high school diploma & 7 & 19.4 & 11 & 31.4 & \\
\hline & High school diploma & 11 & 30.6 & 8 & 22.9 & \\
\hline & Associate degree and higher & 12 & 33.3 & 13 & 37.1 & \\
\hline \multirow[t]{3}{*}{ Job status } & Employee & 10 & 28.6 & 11 & 31.4 & \multirow[t]{3}{*}{$0.379^{*}$} \\
\hline & Self-employed & 8 & 22.9 & 6 & 17.1 & \\
\hline & Other & 17 & 48.6 & 18 & 60.5 & \\
\hline \multirow[t]{2}{*}{ History of hospitalization } & Yes & 16 & 44.4 & 18 & 61.4 & \multirow[t]{2}{*}{$0.55 * *$} \\
\hline & No & 20 & 66.6 & 17 & 48.6 & \\
\hline \multicolumn{2}{|l|}{ Age (years) } & \multicolumn{2}{|c|}{$48 \pm 18$} & \multicolumn{2}{|c|}{$54 \pm 13.6$} & $0.75 * * *$ \\
\hline
\end{tabular}

* Chi-square $\quad * *$ Fisher's exact test $* * *$ t-test

This analysis indicated that there was no significant difference between patients stress score before and after intervention in the control group, but stress scores decreased after the intervention in comparison to the patients stress score before intervention in the intervention group; and the difference was statistically significant. (Table 2) 
Table 2. The level of stress of patients in control and intervention groups before and after intervention

\begin{tabular}{|l|c|c|c|c|}
\hline \multicolumn{2}{|c|}{ Group } & Mean \pm SD & Mean \pm SD & P-value \\
\cline { 3 - 5 } \multicolumn{2}{l|}{ Variable } & Before & After & \\
\hline Stress & Intervention & $12.4 \pm 3.56$ & $8.23 \pm 3.24$ & $\begin{array}{l}\mathrm{P}=0.001 \\
\mathrm{t}=7.38\end{array}$ \\
\cline { 2 - 5 } & Control & $12.37 \pm 2.82$ & $11.9 \pm 4.20$ & $\begin{array}{l}\mathrm{P}=0.08 \\
\mathrm{t}=0.26\end{array}$ \\
\hline
\end{tabular}

Based on this study, no significant difference was observed between intervention and control groups before intervention in terms of stress. After intervention, there was a significant difference between both groups in terms of stress level; and the stress level decreased significantly in the intervention group. (Table 3)

Table 3. Comparison of stress level between intervention and control groups before and after intervention

\begin{tabular}{|c|l|c|c|c|c|}
\hline \multicolumn{2}{|c|}{ Group } & Mean \pm SD & \multicolumn{2}{c|}{ Mean \pm SD } & \multicolumn{2}{c|}{ P-value of independent t } \\
\cline { 2 - 5 } Variable & Pre-intervention & Post-intervention & Before & After \\
\hline \multirow{2}{*}{ Stress } & Intervention & $12.4 \pm 3.56$ & $8.23 \pm 3.24$ & $\begin{array}{c}\mathrm{P}=0.93 \\
\mathrm{t}=0.83\end{array}$ & $\begin{array}{c}\mathrm{P}=0.001 \\
\mathrm{t}=-4.99\end{array}$ \\
\cline { 2 - 5 } & Control & $12.37 \pm 2.82$ & $11.9 \pm 4.20$ & \\
\hline
\end{tabular}

The results indicated that there was a significant difference between two groups in terms of satisfaction level after the intervention; and the satisfaction level was higher in the intervention group than the control group. (Table 4)

Table 4. Evaluation of satisfaction of patients in intervention and control groups after intervention

\begin{tabular}{|c|c|c|c|c|}
\hline Group & \multicolumn{2}{|l|}{ Intervention } & \multicolumn{2}{c|}{ Control } \\
\cline { 2 - 5 } & Mean & SD & Mean & SD \\
\hline Satisfaction & 249.26 & 26.7 & 236.10 & 23.71 \\
\hline & & & & \\
\hline
\end{tabular}

\section{Discussion}

The results indicated a significant decrease in the level of stress after intervention. According to the literature review, there was no previous study on the effects of a welcome program on stress rates in hospitalized patients. Given that a welcome nurse played an important role in introducing and giving information to the patients, the present study was consistent with a study by Hanifi et 
al. In the present study, it was argued that the introduction program could decrease the rates of anxiety, stress, and depression in patients undergoing coronary angiography (15). Hanifi et al. did not examine the rates of stress, anxiety, and depression before intervention, while the present study measured the pre-intervention stress variable to achieve more reliable results. In another study by Chan, the introduction program for patients could reduce patient's anxiety (20). Dehghani's research indicated that familiarizing patients with and informing them about the process of coronary artery bypass surgery would reduce patients' anxiety (21). In a study by Ganji et al., it was also found that pre-admission education could reduce anxiety in patients awaiting catheterization (22). The present study illustrated that a welcome nurse could increase patient satisfaction in the CCU. In this regard, Varaei et al. showed that familiarizing patients with hospital-related affairs could satisfy those undergoing angiography (23). Another study by Nikbakht et al. portrayed that nursing consultation with patients prior to endoscopy increased patient satisfaction (24). The results of the present study were consistent with findings of the above studies.

According to the researchers, fear of the unknown and the lack of enough information may increase anxiety and stress in patients with heart problems (25). Therefore, a welcome nurse was able to relieve stress in patients with acute coronary syndrome in the CCU by familiarizing patients with hospital, nurses, and physicians and giving them information about their disease and the treatment processes. Furthermore, preoperative patient education and counseling based on the patient's individual needs can reduce the stress of patients undergoing cardiac surgery (26). In this regard, a welcome nurse acquaints patients with hospital-related issues and gives them necessary information at the beginning of admission and also improves the status of those with coronary artery disease and increases their satisfaction by playing multiple roles or by investigating their individual needs, such as feelings, fears and worries.

\section{Conclusion}

The results suggested that relevant authorities need to plan for the implementation of a welcome program (familiarization protocol) in health centers to improve some cases, resolve psychological problems that affect the healing process, and improve taking care of them.

\section{proposal}

It seems that training special nurses for appropriate communication with patients as welcome nurses according to standard familiarization protocol may affect psychological problems caused by diseases, patients and their satisfaction levels.

\section{Acknowledgements}

The present paper was derived from a research project that was approved by Deputy of Research and Technology at Zanjan University of Medical Sciences (ethics code: ZUMS.REC.1395.52); hence, the researchers are grateful for all those who assisted us in the present research.

\section{References}


1. Talebizadeh N, Haghdoust Aa, Mirzazadeh A. An epidemiological model (markov chain) of cardiovascular disease in Iran. payesh. 2009;8(2):163-70

2. Hasanpour Dehkordi A, Motaarefi H, Afzali S. Stress level and coping with in patients suffering myocardial infarction. J Res Dev Nurs Midw. 2007; 1(11):15-20. [persian].

3. Brunner Ls. Brunner \& suddarth's textbook of medical-surgical nursing: lippincott williams \& wilkins; 2010.

4. Dalir Z, Houshmand P, Esmaeili H, Hasan Zm. A comparison of cardiac patient's and nurse's perception of illness and hospital stressors: a holistic approach. Journal of Sabzevar University of Medical Sciences. 2003; 10(1): 76-83. [persian].

5. Hanser Sb, Mandel Se. The effects of music therapy in cardiac healthcare. Cardiol Rev. 2005; 13(1):18-23.

6. Krantz Ds, Kop Wj, Santiago Ht, Gottdiener Js .Mental stress as a trigger of myocardial ischemia and infarction. Cardiol Clin. 1996; 14(2):271-87.

7. Heikkilä J, Paunonen M, Laippala P, Virtanen V. Nurses' ability to perceive patients' fears related to coronary arteriography. J Adv Nurs. 1998; 28(6):1225-35.

8. Karimi H, Taheri N, vashhani B, Vaghee S, Yavari M. The effect of communication skills training on the quality of nursing care of patients. Evidence Based Care. 2013; 2(4):37-46.

9. Moir C, Roberts R, Martz K, Perry J, Tivis L. Communicating with patients and their families about palliative and end-of-life care: comfort and educational needs of nurses. Int J Palliat Nurs. 2015; 21(3):109-12.

10. Alston C, Paget L, Halvorson G, Novelli B, Guest J, Mccabe P, Et Al. Communicating with patients on health care evidence: institute of medicine of the national academies; 2012

11. Mccabe C. Nurse-Patient communication: an exploration of patients' experiences. J Clin Nurs. 2004; 13(1):41-9.

12. Gholjeh M, Dastoorpour M, Ghasemi A. The relationship between nursing care quality and patients satisfaction among hospitals affiliated to Zahedan University of medical sciences in 2014. Jorjani. 2015; 3(1):68-81.

13. Findik Uy, Unsar S, Sut N. Patient satisfaction with nursing care and its relationship with patient characteristics. Nurs Health Sci. 2010; 12(2):162-9.

14. Hanifi N, Bahraminejad N, Mirzaei Kat, Ahmadi F, Khani M, Taran L. The effect of orientation program on stress, anxiety and depression of patients undergoing coronary angiography.I.J.N.R. $2012 ; 7(25): 1-8$.

15. Crawford Jr, Henry Jd .The depression anxiety stress scales (dass): normative data and latent structure in a large non-clinical sample. Br J Clin Psychol. 2003; 42(2):111-31. 
16. Henry Jd, Crawford Jr. The short-form version of the depression anxiety stress scales (dass-21): construct validity and normative data in a large non-clinical sample. Br J Clin Psychol. 2005; 44(2):227-39.

17. Sahebi A, Asghari Mj, Salari Rs. Validation of depression anxiety and stress scale (dass-21) for an iranian population. Iranian Psychologists. 2005;4(1):36-54.[persian]

18. La Monica El, Oberst Mt, Madea Ar, Wolf Rm. Development of a patient satisfaction scale. Res Nurs Health. 1986; 9(1):43-50.

19. Nikmanesh P, Kavosi Z, Sadeghi A, Yusefi Ar. Effect of communication skills training of nurses on patient satisfaction about nursing services in hospitals affiliated to shiraz university of medical sciences. jhosp. 2018; 17(2):59-70. [persian]

20. Kit Chan Ds, Cheung Hw. The effects of education on anxiety among chinese patients with heart disease undergoing cardiac catheterization in hong kong. Contemp Nurse. 2003;15(3):310-20.

21. Dehghani H., Dehghani Kh., Nasiriani Kh, Banaderakhshan H. The effect of familiarization with cardiac surgery process on the anxiety of patients undergoing coronary artery bypass graft surgery. Modern Care Journal.2013; 10(4):257-263. [persian]

22. Ganji T, Taleggani N, Haghani H. The effect of teaching on the level of anxiety and knowledge of patients before cardiac catheterization. IJN. 2004;17(38):51-7.[persian]

23. Varaei Sh, Keshavarz S, Nikbakhtnasrabadi A, Shamsizadeh M, Kazemnejad A. The effect of orientation tour with angiography procedure on anxiety and satisfaction of patients undergoing coronary angiography. Iranian Journal of Psychiatric Nursing. 2013; 1(2):1-10. [persian]

24. NikbakhtNasrabadi A, Bakhshayeshi O, Parsayekta Z, Hoseyni M, Taghavi T, Rezvani H. The effectiveness of implementing nursing consultation on the anxiety of patients undergoing GI endoscopy. IJN. 2012; 25(79):54-62. [persian]

25. Leske JS. Cardiac catheterization: the patients' perspective .Aorn Journal. 1995; 62(5):819-20.

26. Jasemi M, Rahmani A, Aghakhani N, Eghtedar S, Alinejad H. The effect of face to face education on anxiety and hemodynamic status of patients who are candidates for CABG surgery. RJMS. 2013; r •(114):28-34.[persian]

\section{Bibliographic information of this paper for citing:}

Biglar S, Rafiee A, Puryaghoob M, ET al. The effects of nursing welcome program on the level of stress and satisfaction of patients in the Coronary Care Unit.

J Res Dev Nurs Midw, 2019; 16(2): 11-18.

Copyright (C 2019, Shahla Biglar, Abolhassan Rafiee, Maryam Puryaghoob, Fariba Sharafi, Fatemeh Moghaddam, Zahra Nisari. 